\title{
An Apparel Brand's Channel Strategy: The Case of Oliver in Korea
}

\author{
Hyejeong Cho, Sungkyunkwan University, South Korea \\ Yanghun Lim, Sungkyunkwan University, South Korea \\ Sungmin Ryu, Ph.D*, Sungkyunkwan University, South Korea
}

\begin{abstract}
The purpose of this case study was to describe the development of a channel strategy for an apparel brand, BoKids, designed to distribute its brand, Oliver, efficiently to customers. Bokids launched its childrens' apparel brand, Oliver, in Korea by signing a brand license contract with Oliver of USA. When the brand was launched in 2005, Oliver was positioned as a brand with a reasonable price and a high quality product, which was sold primarily through department stores. In 2007, Oliver was suffering from sluggish sales volumes, and switched its main distribution channel from department stores to discount stores, which are the number 1 retail format in Korea. Oliver was compelled to adjust the price range of its main products to $\$ 20-30$ in order to satisfy the needs of discount store customers. However, Oliver has considered Internet shopping as another channel for the Oliver brand, as Internet shopping is rapidly gaining popularity in Korea. This case can be used in conjunction with discussions on marketing topics, such as the design of marketing channels (Chapter 6, Designing the Marketing Channel, "Marketing Channels: A Management View," $7^{\text {th }}$ Edition by Bert Rosenbloom, South-Western College Pub, 2007) for senior level marketing seminars.
\end{abstract}

Keywords: Marketing Channels, Channel Design, Retailer types

\section{INTRODUCTION}

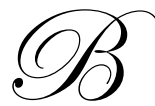

okids launched its kids' apparel brand, Oliver, in Korea by signing a brand license contract with Oliver of USA, a world famous kids' apparel brand. Oliver of USA boasts 90-years of history, and has been recognized as the No. 1 kids' apparel brand with high-quality products as well as very reasonable prices.

Bokids' Oliver in Korea (hereafter referred to as Oliver) introduced strategically planned products, developed natural materials providing comfortability and durability, and operated a just-in-time production system.

Upon its launch in 2005 , Oliver was positioned as a reasonably priced and high-quality brand, which was sold primarily in department stores. However, Oliver decided to cut its prices by $15-20 \%$ in December of 2005, as its prices were deemed to be higher than those of its competitor brands in department stores. In line with the price cut, the company decided to expand its direct import line, from 5\% to 30\% of total sales.

In October 2006, Oliver re-positioned itself as a denim-specialty brand and expanded its denim line, one of the strong points of the brand. Additionally, Oliver transformed its organization from a brand license-based production to a direct import company in order to reinforce its brand originality. While expanding its denim line, Oliver reduced the size of its infant line, and reset its main target group to the 4-8 year old age group.

In 2007, Oliver switched its main distribution channel from department stores to discount stores, and adjusted the price range of its primary products to $\$ 20-30$, in an effort to conform to discount store customers' budgets. As Oliver changed its focus to direct imports, it implemented a cost-saving sourcing system through the direct importation of products from the production site in China rather than importing from the headquarters in the United States. The company also implemented a direct order system from overseas production sites to adjust the design and fit when the design and materials were not concordant with the demands of the domestic market.

As the result of changes in product position and channel strategies, Oliver is faced with the need to overhaul its channel strategy and select relevant distribution outlets. Lots of apparel brands are diversifying their distribution channels in order to cope with department stores' absurd requests-i.e. unreasonably high sales commission rates. Among outlets, such as department stores, discount stores, franchise shops, and Internet shopping, Oliver should select the proper combination of distribution outlets in order to efficiently distribute its clothes to customers.

\footnotetext{
* Contact Author
} 


\section{CURRENT SITUATION OF APPAREL DISTRIBUTION IN KOREA}

Total apparel and fashion market size is expected to reach $\$ 21$ billion in 2007, a 3.7\% year-on-year growth. Consumption recovery was delayed in the first half of 2007 due to the strength of the Korean Won against the US dollar, in addition to high oil prices. In the second half of 2007, consumption appeared to have recovered to some degree, as indicated by the increase in the consumer expectation index to over 100, principally as the result of a bullish stock market, economic recovery, and improved household expectations for the economy (see Table 1).

Table 1: Market Size and Growth Rate of Apparel Sales

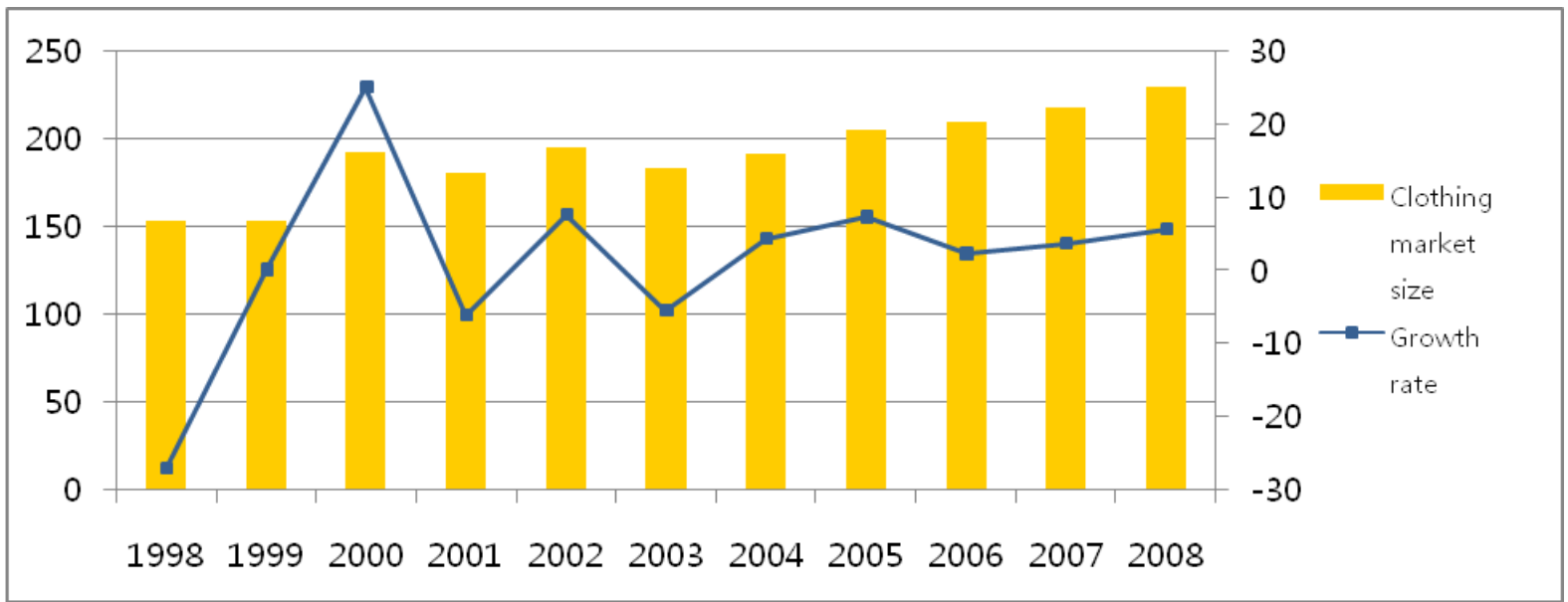

Source: Daishin Securities Co, Hana institute of finance

It is indicated that the portion of infants and children's wear has been on the increase in Korea's fashion market. As presented in Table 2, infant and children's wear took $36.8 \%$ of the total fashion market in 2008 which increased $33.1 \%$ from 2007. Whereas it shows that the other apparel categories including sportswear, character casual, and ladies' wear have decreased.

Table 2: Ratio Changes Per Clothing Type

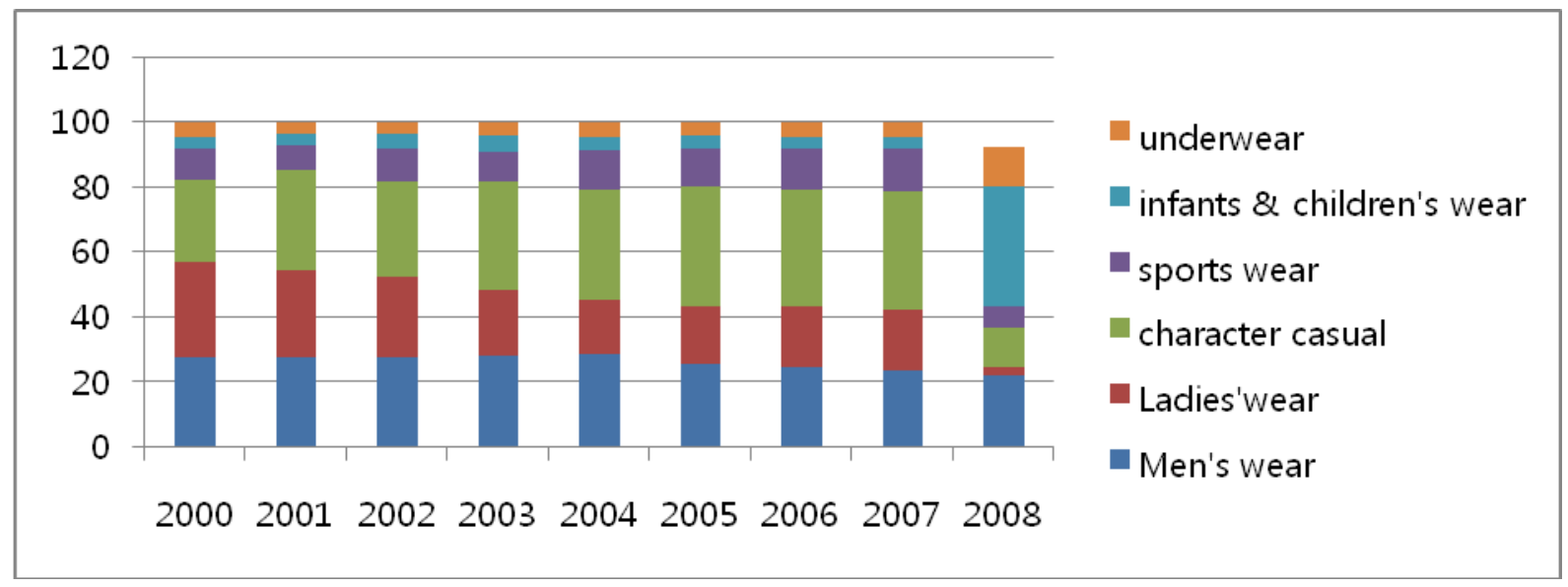

Source: Korean Textile Industry Association

The most visible changes in Korean channels of distribution are the increasing market shares of discount stores, and the rise of Internet shopping. These two channels have stolen the market share of previously dominant 
channels, most notably department stores and traditional street vendor markets.

As shown in Table 3, discount stores and outlets recorded robust sales growth, which has altered the rankings of each of these distribution channels. Discount store sales already exceed those of department stores, and the gap between these two channels has widened.

Department stores have recently recorded very slow sales growth and now command the second-largest market share of distribution channels in Korea. Internet-based distribution channels are expected to surpass department stores soon in terms of the 2008 market share. Discount stores are responsible for the preponderance of market share, whereas the traditional street vendor market and others are showing negative sales growth.

Table 3: Market Share of Main Retail Distribution Channels in 2007

\begin{tabular}{|c|c|c|c|c|c|}
\hline \multicolumn{2}{|c|}{ In Trillion Won } & 2005 & 2006 & 2007 & YoY sales growth 07 \\
\hline \multicolumn{2}{|c|}{$\begin{array}{c}\text { Traditional Street Vendor } \\
\text { Market }\end{array}$} & 88.0 & 86.8 & 85.0 & $-2.2 \%$ \\
\hline \multicolumn{2}{|c|}{ Department Store } & 17.2 & 17.9 & 18.7 & $4.5 \%$ \\
\hline \multicolumn{2}{|c|}{ Discount Store } & 23.6 & 25.4 & 27.7 & $9.1 \%$ \\
\hline \multirow[t]{2}{*}{ Mail Order } & $\begin{array}{l}\text { TV Home } \\
\text { Shopping }\end{array}$ & 1.7 & 4.5 & 4.8 & $6.7 \%$ \\
\hline & Internet & 10.7 & 13.1 & 15.9 & $21.4 \%$ \\
\hline \multicolumn{2}{|c|}{ Factory Outlets } & 4.6 & 5.2 & 5.9 & $130 \%$ \\
\hline
\end{tabular}

Source: Shinsaegae Distribution Research Institute, Korea National Statistics Office

\section{Department Store}

In Western countries, department stores make profits through the difference between the price they pay to their suppliers and the price at which they sell the product to their customers. The majority of the famous department stores in the United States and European countries purchase all kinds of products from designers and makers, and sell the products to customers by adding appropriate margins to them. Thus, they develop a variety of marketing tools to increase sales volume, and implement their own inventory process systems.

Department stores in Korea make money principally by renting space to suppliers. Usually, they establish a sales commission, which is $35-40 \%$ of the sales price brand suppliers demand from consumers. Those sales commissions account for $80-90 \%$ of department stores' sales. Korean department stores depend solely on the sales commissions paid by brand suppliers resulting in constant issues of excessive commissions charged to weak brand suppliers.

Department stores have exercised their absolute power on apparel brand suppliers, as they are one of the principal distribution channels for apparel brand suppliers. Therefore, there have been some cases of unfairness and wrongdoing on the part of department stores. Department stores force brand suppliers to pay very high sales commissions and to share additional costs. For instance, apparel suppliers have complained about absurdly high sales commissions, as well as a variety of sales event participation fees, including enforced-sales, shared advertising costs, product renewal costs, etc. (see Table 4 below). The problem is that those high commissions actually raise the retail price.

Table 4: Department Stores’ Injustice Business Practices

\begin{tabular}{|c|l|l|}
\hline \multicolumn{1}{|c|}{ Type } & \multicolumn{1}{c|}{ Case } \\
\hline Type1 & $\begin{array}{l}\text { Transferring costs to } \\
\text { brand suppliers }\end{array}$ & - Transferring costs occurred by department stores' promotion events \\
\hline Type2 & Enforcing to take loss & $\begin{array}{l}\text { - Enforcing brand supplier to take loss caused by department store's mistake to } \\
\text { put wrong price tag } \\
\text { - Pushing brands to participate in department store's promotion }\end{array}$ \\
\hline Type3 & Entertainment cost & - Department stores' purchasing managers force brand suppliers to treat them. \\
\hline
\end{tabular}

Source: The Hankyorah Newspaper, 11/10/2006 


\section{Discount Stores}

Discount stores are looming as a next-generation channel for the apparel industry, as they reinforce the fashion business while attempting to change them into "lifestyle stores". Although there is fierce competition among apparel brands in discount stores, apparel brands still attempt to launch brands for discount stores. This is attributable primarily to the fact that approximately seven new brands launch every new season, and discount stores are often considered the main distribution channel for these new brands. Brands that rely primarily on department stores are also constantly attempting to increase their sales share in discount stores.

Discount stores also charge 15-20\% sales commissions to apparel brands for renting fees. As discount stores request lower sales commissions than do department stores, apparel brands tend to rely more heavily on discount stores than department stores. All apparel brands, including women's, men's, casual, and sports apparel brands are desperately attempting to enter the discount store market. Discount stores are, therefore, increasing their market share of apparel sales and have evidenced the highest levels of sales growth in the past couple of years. This is why discount stores compete with department stores to become a principal channel for kids' apparel.

As consumers are attracted by the relatively low prices of discount stores, there is an increasing demand for discount store space. Because approximately seven new brands are launched every new season, the demand for discount store space continually rises. The problem with this is that competition among kids' apparel brands becomes severe, which results in a high commission rate for kids' apparel brands in discount stores. Discount stores emulate, to some degree, the bad behavior engaged in by department stores. Discount stores tend to charge high sales commissions, as do department stores. They also engage in the chronic unjust practices associated with department stores, including high sales commissions, sharing the labor costs of the sales staff, and various types of promotion costs. In addition to sales commissions, the discount store requests brand suppliers to pay logistics costs and to share the labor cost of part-time sales staff. Thus, the total charges levied by discount stores accounts for almost $30 \%$ of total sales volume.

Another unjust business practice of discount stores is that, although they purchase and sell the products under their own responsibility, they are not responsible for the inventory of apparel brands. Discount stores pretend to undertake inventories, but they actually force the apparel brand supplier to accept unsold products. They transfer the entirety of the inventory burden to brand suppliers. For example, if they require 100 items, they order 200 items and simply return inventory goods after the season passes. According to the brand suppliers, some foreignfranchised discount stores purchase goods for credit and delay payments in order to deduct various costs afterwards.

Discount stores' best competitive edge is their low prices. As such, their sales prices cannot exceed 3-3.5 times the manufacturing cost. Considering their frequent sales promotion events, it has been estimated that discount stores cannot make profits if they continue to increase sales commissions. Taking into account sales commissions of $25 \%$, intermediate management commissions of $15 \%$, manufacturing costs of $30 \%$ and constant discount rates of 5\%, brand suppliers' profitability hovers around $25 \%$. However, considering factors such as the over 50\% promotion event rates and inventory rates, brand suppliers tend to experience difficulties in making profit.

\section{Internet Channel}

Because Internet selling was so severely hit by the burst of the "dotcom bubble" at the end of 1990, it has been reborn as a reliable distribution channel. The Internet has developed into one of the major global distribution channels, and has good future prospects in Korea.

The internet channel recorded a 29.5\% year-on-year average sales growth in Korea between 2001 and 2007, primarily due to the fact that Korea boasts the world's highest internet broadband penetration. Since the system was stabilized in 2003, the internet channel enjoyed a 22.3\% year-on-year average sales growth, reaching a total market size of $\$ 15$ billion in 2007.

Consistent with the growth of the overall internet channel, Internet apparel sales enjoyed a $57.8 \%$ year-onyear sales growth during the period between 2001 - 2007. Coupled with general sales growth, the contribution of apparel sales to the total internet channel expanded from 5.3\% in 2001 to $17.2 \%$ in 2007, and this trend is expected to continue until 2010. According to the National Retail Federation, apparel on-line sales caught up with computer on-line sales in 2006, after travel on-line sales surpassed computer on-line sales. . ( see Table 5 below) 
Table 5: Apparel Sales Volume in Internet

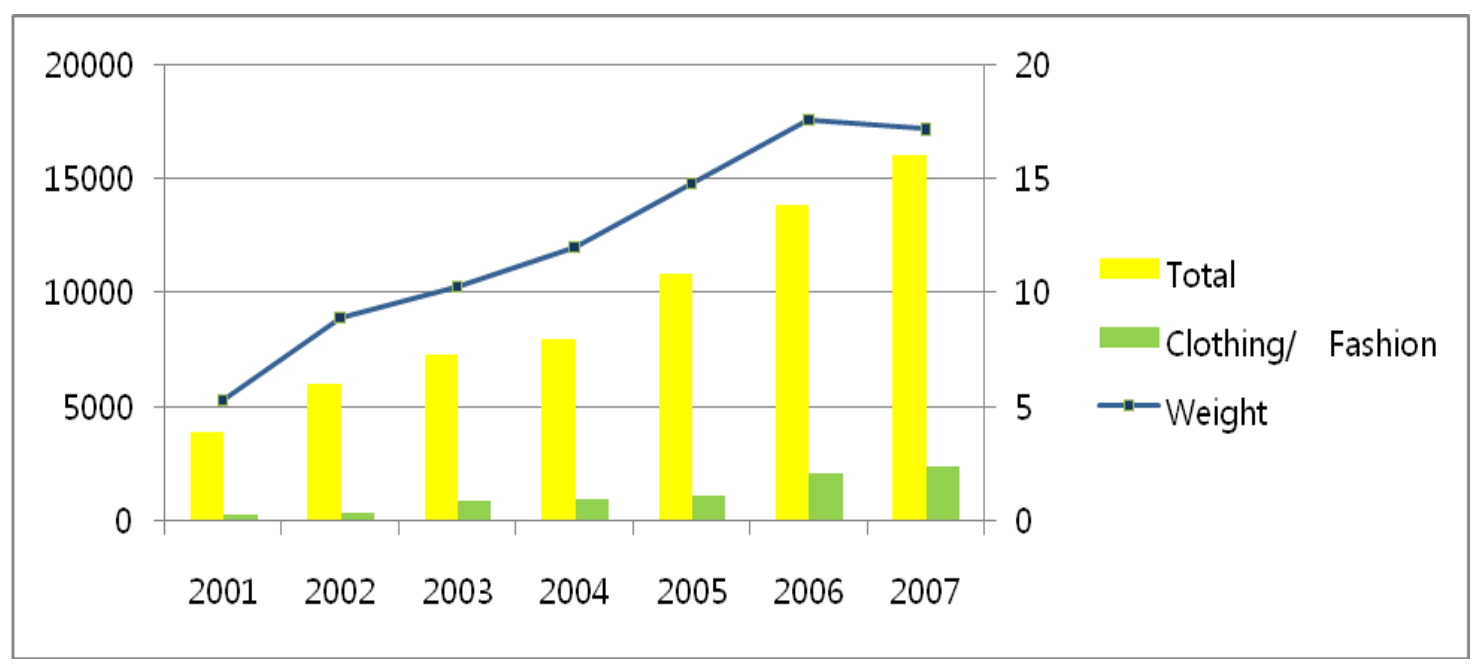

source: Korean Statistical Information Service

Even though the contribution of the internet channel to the total kids' apparel market is not overly large, the internet channel for kids' apparel is growing. Kids' apparel sales on the internet have increased actively at an average growth rate of $15 \%$ per year. As internet channels offer inexpensive prices, young parents who are relatively poor tend to prefer to use internet channels. Another advantage of the internet channel for kids' apparel is that it is generally easier to establish the fit of kids' apparel than to do so for adult apparel. Kids' apparels are also not restricted to fit, which is not the case with adult apparel.

However, the internet channel also has its inherent disadvantages. Apparel brand suppliers must bear a huge inventory due to returned goods. In particular, the return rate for apparels has been reported to be as high as $30 \%$. In extreme cases, customers have returned clothes after wearing them on several occasions, and companies must dispose of this used clothing.

\section{Franchise}

Franchise is one of the main channel for the sales and distribution of kids' apparel. Many kids' apparel brands face intense competition in discount stores, and suffer from the extremely low price policies of the discount store. Thus, apparel brands with high quality brands launch franchises because they experience difficulties in attempting to emulate the low price policies of the discount stores. Therefore, higher-priced brands tend to rely more heavily on franchises.

Kids' apparel brands are recruiting franchise dealers as an alternative to cope with declining department store sales. As department stores are currently suffering from low overall sales growth, higher-priced brands have no real choice but to rely more on franchises than before.

Relatively new brands such as 'Our Q Junior' with 84 shops, 'Marueye' with 45 shops, and 'Oceansky' with 55 shops, are actively opening franchise shops. These new brands tend to open their franchise shops in downtown areas of suburb cities like Wonju, Bupyung, and Cheonan, enjoying higher margins than other established brands. In addition, these new brands complement their weaknesses as market followers by offering differentiated commission rates based on franchisees' careers and shop locations. After opening shops, brands increasingly support promotion activities, supplying popular basic items, affluent event items, and promotion gifts.

Kids' apparel franchisees have been directly hit by the overall economic slowdown, as well as the extremely low-priced goods supplied by discount stores. Kids' brands have experienced difficulties in dealing with the reduction in sales of their franchise shops. In particular, they have feuded with franchisees as they have increased the price of their goods.

While infant apparel sales have expanded significantly recently as the result of increased marriage rates and birth rates, kids' apparel sales volumes accounted for only $3.7 \%$ of total apparel sales this year, which represents a $0.1 \%$ point increase from last year. As Korean households increase their education expenditures, they have reduce 
spending on clothes. In an effort to cope with sluggish sales, kids' apparel brands have begun to diversify their distribution channels. Bokids has also diversified the distribution channels exploited for the distribution of its kids' brand, Oliver, to discount stores, in addition to existing department stores.

\section{ALTERNATIVE CHANNEL STRATEGIES FOR OLIVER}

Oliver is divided into a "pretty girl" line and a "sporty boy" line, based on the American-style "casual wear" concept, exemplified by such products as hickory denim. This brand was mainly targeted to the $0 \sim 7$ year age range, with a sub-target of the 8 11-year age range, when it launched. However, the brand increased its main target age to $4 \sim 8$ years old, and now covers up to the maximum age of 11 years.

The brand began with department stores as a main channel, as its American partner asked BoKids to position Oliver as a high-quality brand. Oliver was forced to cut prices because its domestic prices were higher than overseas prices. However, Oliver posted sluggish sales in department stores, and thus it had to rely more heavily on discount stores than before. Oliver later decided to rely more than before on discount stores, while maintaining its presence in department stores. However, consumers may become confused with the brand's image, as the same brand is sold via different types of channels. BoKids developed an experimental denim brand and cut its prices by $15 \sim 20 \%$ to position itself as a discount store brand.

As Oliver changed its distribution channel from department stores to discount stores, they are expected to command sales of $\$ 10$ million in 2007 , representing a stalwart $119.0 \%$ year-on-year growth, escaping from the huge operating losses of last year to reach a break-even point this year. Oliver, however, faces difficulties in building strong consumer recognition among discount store consumers. Consumer recognition of Oliver is far behind that of Bluedog, the market leader in department stores, and is somewhat lower than that of Curleysue, a brand in the same price range as Oliver. It also has a lower recognition level than Eland Junior, which is strong in the franchise channel.

Oliver sells the same apparel in department stores and discount stores. This strategy runs the risk of extending its department store image to the discount store. Oliver must develop a strategy to identify a unique position in order to resolve this problem. Considering these factors, we can suggest the following strategies to Oliver.

\section{Focusing on Department Store}

Currently, Oliver sells its apparel through 12 department stores. Some unjust business practices were engaged in by the department stores, as mentioned above. However, some department stores have promised to correct their unethical behaviors and to attempt to develop a healthy relationship with apparel brand suppliers. Those changes are as follows;

\section{Adjusting Commission Rates, Depending on Sales Volume of Apparel Brand}

Basic commission rates are established by discussions between department stores and brand suppliers, whereas department stores charge lower commission rates on sales in excess of target sales. This means that department stores provide sales benefits to the brand suppliers who contribute to their bottom lines.

\section{Reducing Costs Paid by Brand Suppliers}

Department stores used to force brand suppliers to share the promotion costs associated with newspaper advertisements, as well as interior decoration costs. Department stores have promised to reduce newspaper advertisement costs and eliminate decoration costs. They have also promised to make it a rule to talk to brand suppliers about participating in promotion events initiated by department stores.

\section{Changing from Cut-off Method to Incubator Method}

Department stores will change the brand supplier selection procedure. They will introduce the 'Incubator Method' in order to identify promising brands, rather than the 'Cut-off Method', which lays off brands if the brands' sales do not achieve the expected level. They must change these methods to support promising brands, even when they are not satisfied with the brands' current sales volumes.

In addition, they will pay brand suppliers in advance when the brands are suffering financially. However, the brand suppliers will afford less weight to department stores' promises, arguing that department stores are correcting unjust practices that should have never been instituted. According to brand suppliers, department stores have made no attempt to alleviate almost $40 \%$ of these sales commissions. 
As mentioned before, department stores are struggling with slow sales increases. Thus, they are now focusing more on high-priced goods than in the past. Oliver, therefore, must devise a strategy to add high-quality lines for sales in department stores. As consumers can readily purchase basic apparel from discount stores, brand suppliers need to develop a range of different products which can be found only at department stores.

\section{Giving up the Department Store and Focusing on the Discount Store}

The second alternative for Oliver would be to reduce the number of its shops in department stores, and to focus more heavily on discount stores. The small number of its remaining shops in departments stores would then function as flagship stores, the principal purpose of which would be to increase brand image (i.e., premium image) among consumers. As brands sold in department stores have the advantage of being perceived as high-quality products, Oliver could use its department store shops to increase their brand image.

Discount stores have recorded an apparel sales volume of $\$ 295$ million in 2006. As department stores pursued a high-class channel strategy for consumers, some kids' apparel brands, including 'Twinkids', 'Eccolier', and 'Michico London \& Junior" have retreated from department stores and pursued discount stores. This trend became apparent when famous brands such as 'Little Bangbang', 'Hangten Kids', and 'Roem girls' began to open shops in discount stores.

Currently, kids' apparel brands have launched exclusive brands for discount stores, including 'Little Bobdog', 'Tuna', 'Pee \& So'. These brands positioned themselves as low-priced and reasonable-quality products by quickly introducing trendy items that were suitable for sale in discount stores.

The popularity of discount stores has also been verified by market research. According to the results of market analysis (see Table 6 below), discount stores have become a principal market for kids' apparel purchases in 2004, along with traditional street vendor and franchise shops. The analysis demonstrates that, in the second half of 2004, consumers used discount stores more than department stores to purchase kids' apparel. This trend in value purchasing is also demonstrated by the fact that consumers are increasingly purchasing kids' apparel from discount outlets, where consumers can buy quality goods at reasonable prices.

Table 6: The Trend of Purchasing Place of Kids Apparel

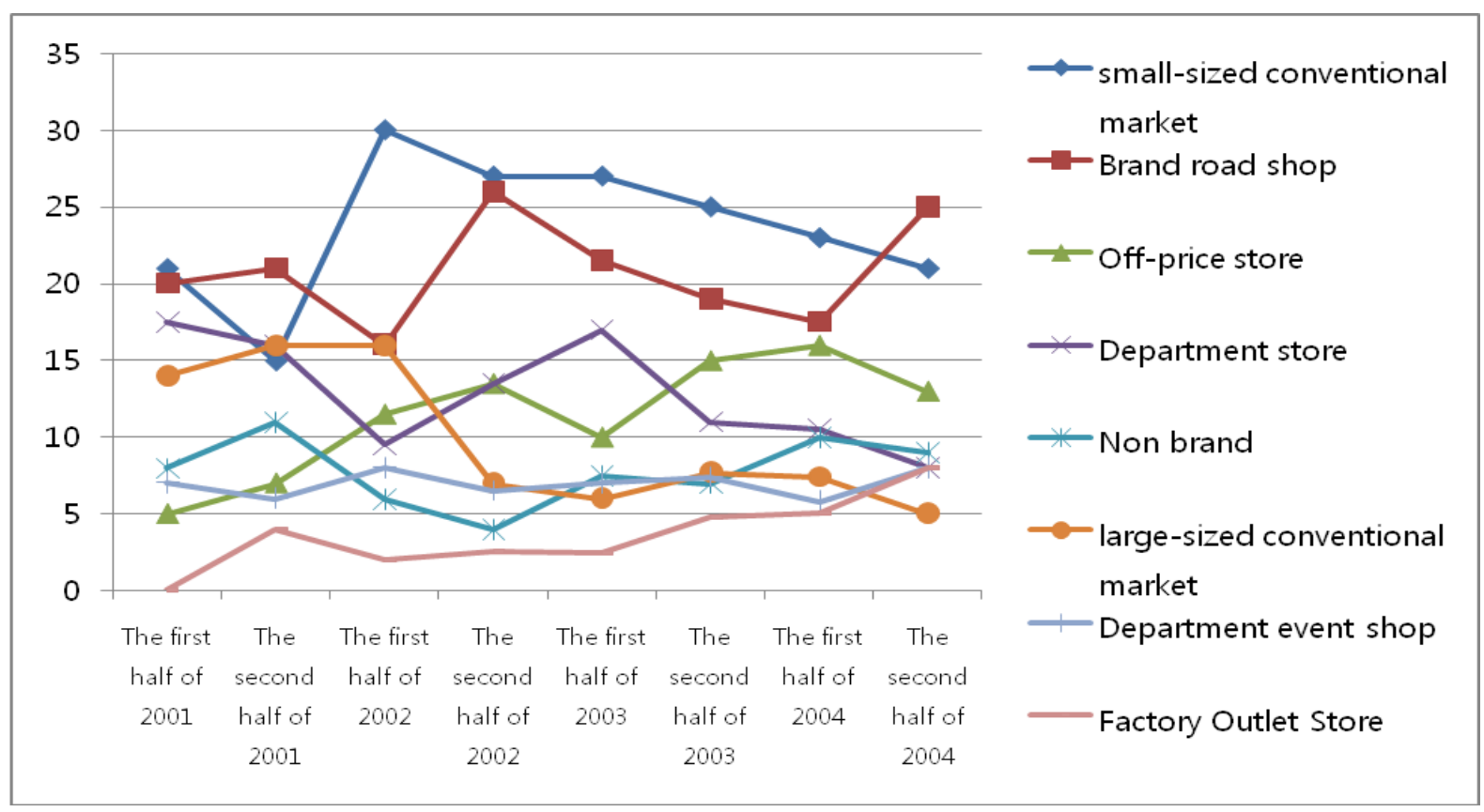

Source: Samsung DesignNet 


\section{Focusing on Internet with Home Shopping}

Kids' apparel brands are now attempting to diversify their distribution channels to include Internet shopping and TV home shopping. For instance, Prokids, a company which ran the 'Baby Heroes' line, recently launched the 'Toto Heroes' line to test on-line sales of a toddler line. After launching their on-line toddler brand, Prokids has experienced a successful outcome, recording monthly sales of $\$ 1.5$ million by smoothly absorbing consumers of infant apparel. Oliver is now running an internet shopping mall, which is connected to its company's homepage. In the internet shopping mall, consumers can select clothes from a long list and receive them within 5-6 business days. However, the high return ratio in the internet shopping channel still causes headaches for internet sellers.

The advantage of the internet channel for kids' apparel lines such as the Oliver brand is that the fitting of kids' apparel is simpler than that of adult apparel. Kids' apparel tends to have less fit restrictions as compared to adult apparel. Additionally, Koreans tend to embrace the Internet aggressively, and purchase many products via the internet. Thus, Oliver should seriously consider internet selling protocols in order to take advantage of its many benefits.

Oliver began to sell some of its apparel through TV home shopping in 2007. At that time, Oliver sold its apparels at $54 \%$ of the market price, and offered its natural baby bath cream as a promotional gift. One of the main problems with home shopping, though, is that the repurchase rate in the home shopping channel is low, and dormant customers account for more than $70 \%$ of total consumers.

Oliver should be careful, however, when utilizing the home shopping channel, as apparel sales in TV home shopping have been recently decreasing. This is due to the fact that TV home shopping charges the highest sales commission rate, $45 \%$, and also has a higher percentage of return rates, at approximately $50 \%$.

\section{Franchise Shop Strategy}

Consumers who frequently purchase clothes at franchise shops tend to prefer well-known brands with a good reputation in the market. Therefore, kids' brands which branched from famous adult brands such as E-land Junior, Little Bangbang, Little Brann, and Tom Kids have maintained stable status in the franchise market for over 10 years. Although new brands such as Mashmaro, Mickey Club, Rugrats, Five \& Ups, and Rorarori have attempted to gain entry to the market, they have failed to achieve a substantial market position.

Meanwhile, other new brands which have branched from well-known adult brands, such as Marueye and Ocean Sky, have exhibited sales growth in the franchise market. They have readily secured franchisees, thanks to their high levels of brand recognition as famous adult brands among consumers. They have found ways to grow as kids' brands by developing their own systems, production capacity, and plan to escape from their positions as merely brother brands of famous adult brands. Brands with high awareness levels enjoy low promotion costs, and also gain advantages from high brand loyalty from franchisees.

The problem with franchise channels is that Oliver does not have a high brand awareness level among consumers. Thus, it is expected that Oliver may have difficulty in recruiting franchisees. Apparel franchisers generally enjoy a power advantage over their franchisees, which allow franchisers to promote their own strategies. Oliver may not enjoy power over franchisees as the result of low brand awareness among consumers. Thus, Oliver should find a way to increase brand awareness for the franchise market.

\section{DECISION POINT}

Oliver should adopt relevant channels (or a combination of multiple channels) to efficiently distribute its products to consumers. You can recommend the single best channel for Oliver. If you recommend multiple channels for Oliver, which channel should be adopted as the main channel? Alternatively, which channel should be adopted as a supporting channel? What factors should be considered for the selection of appropriate channels for Oliver?

\section{TEACHING NOTES}

\section{Overview}

The purpose of this case is to enhance students' understanding of how to develop a good channel strategy for a brand which has recently launched its product. By applying an existential-phenomenological description of distribution of channels in Korea, this case will describe how an apparel brand should deal with a rapidly changing channel environment. The students should be able to deepen their understanding of channel strategy in a macro 
social context.

\section{Case Description}

Oliver was originally positioned as a reasonably-priced and high-quality product, which was sold principally through department stores. Oliver, which suffered from sluggish sales volumes, switched its main distribution channel from department stores to discount stores, the number of which is growing rapidly in Korea. Oliver had to adjust the price range of its main products to $\$ 20-30$ in order to satisfy discount store customers. However, Oliver has considered adopting the Internet channel and franchise shops as another channel for Oliver to exploit. Internet shopping is undergoing rapid growth in Korea, and franchises have constituted a principal channel for the apparel industry.

\section{Case Preparation}

Several approaches may be utilized to prepare students before they analyze this case. However, it is strongly recommended that students have some understanding of marketing channel management and distribution management for apparel brand suppliers.

Students need to understand the factors that influence channel management decisions, in addition to the complexity inherent to managing multiple channel relationships. Reading assignments before class, e.g. Chapter 3, The Environment of Marketing Channels, and Chapter 6, Designing the Marketing Channel, from "Marketing Channels: A Management View," 7th Edition, by Bert Rosenbloom, South-Western College Pub, 2004, will be quite helpful to students in their analyses of this case.

This case has a level of complexity appropriate for graduate-level or upper-division undergraduate courses. It is designed to be taught over one class period, depending upon the instructor's approach. Students are expected to spend between 2 to 3 hours of outside preparation time, depending upon the instructor's choice of preparation.

\section{Case Synopsis}

Bokids launched its kids' apparel brand, Oliver, in Korea by signing a brand license contract with Oliver of USA. Upon its Korean launch in 2005, Oliver positioned itself as a reasonably-priced and high-quality product brand, which was to be sold principally through department stores. In 2007, Oliver suffered from sluggish sales volume, and switched its main distribution channel from department stores to discount stores, which are increasing rapidly in Korea. Oliver was forced to adjust the price range of its main products to $\$ 20-30$ in order to satisfy discount store customers. However, BoKids has considered using Internet shopping as another channel for Oliver, as Internet shopping has become increasingly popular in Korea.

\section{Intended Audience and Course Placement}

This case is primarily appropriate for graduate-level or upper-division undergraduate students taking a marketing channel management course. The case should be introduced after students have read the relevant chapters on supply chain management or buyer-supplier relationship management (Chapter 3, The Environment of Marketing Channels, "Marketing Channels: A Management View," 7th Edition by Bert Rosenbloom, South-Western College Pub, 2004). Since this case covers multiple consideration factors in channels of distribution management, this case is recommended as a comprehensive case. An undergraduate course instructor may also use this case for an end-ofchapter discussion in supply chain management.

\section{Learning Objectives}

The overall objective of this case is to introduce students to the complex considerations inherent to channel management. In this case, students tend to experience difficulty in making channel decisions faced by managers in real business situations, namely, those that require making a decision as to whether one should build and enforce existing channels or, rather, seek other channels of distribution. Students will explore the decision factors for analysis. Specific learning objectives are as follows:

1. For students to obtain an understanding of the factors influencing channel design.

2. For students to understand and appreciate the difficulties inherent to making decisions under rapidly changing environments.

3. For students to understand the factors influencing multiple channels.

4. For students to understand the importance of social mechanisms in managing the marketing channel upon the occurrence of declining and growing channels, such as department stores and discount stores. 


\section{Case Analysis}

In Korea, traditional street vendor markets played a key role as the primary apparel distribution channels prior to the 1980s. Department stores and franchise shops emerged as new main channels for an increasing number of kids' apparel brands beginning in the 1980s.

Among these channels, department stores' market share accounts for $25 \%$ of the apparel market and a great number of premium apparel brands are targeted toward department store consumers. Apparel brand suppliers, therefore, tend to regard department stores as important business partners. However, apparel suppliers must, in that case, also absorb the high commission fees of $35-40 \%$, along with the many types of extra fees charged by department stores. Department store brands enjoy the premium image conveyed by department stores. Thus, apparel suppliers who position their brands as premium brands should consider department stores as the best channel to convey the image of a premium brand.

Meanwhile, discount stores have recorded an $18.8 \%$ year-on-year average growth in apparel sales, whereas the total domestic apparel market size has undergone a 1.3\% year-on-year average decrease over the past four years. Discount stores' market share in the apparel market has increased from $7.5 \%$ in 2001 to $15.8 \%$ in 2005 . Large discount stores continue to introduce apparel brands. However, discount stores also continue to increase their sales commissions, which often causes conflicts with apparel brands.

As franchises allow apparel brands to cover markets without incurring huge expenses, franchise shops have proven to be a principal channel for apparel brands that are small or medium-sized companies. However, franchisees have been directly hit by the overall economic slowdown, and major apparel brands that rely mainly on franchises have been severely damaged by the apparel sales of discount stores.

It is a good idea to monitor newly introduced distribution channels, such as internet channels. Korean consumers have internalized e-commerce, and now actively purchase products over the internet. The internet is, therefore, expected to bypass department stores and become the number two retail format in 2009. However, apparel brands who sell over the internet continue to suffer from the high ratio of returned clothes. Thus, companies must find some way to reduce their return ratio, in order to effectively exploit internet sales.

Multiple channels have become popular over the past decade, partially as the result of the development of Internet shopping (Geyskens, Gielens, \& Dekimpe 2002). Multiple channels provide the advantage of wide market coverage to firms (Rosenbloom, 2004). As Oliver is a relatively new brand to the Korean market, it should consider the use of multiple channels to quickly cover the market.

\section{AUTHOR INFORMATION}

Hyejeong Cho is a doctoral student at Sungkyunkwan University. She is interested in the areas of retailing, consumer behavior, and fashion marketing.

Yanghun Lim is a doctoral student at Sungkyunkwan University. He is specialized in the areas of channels of distribution, business-to-business marketing, and global marketing channels. He has publications in Journal of Business-to-Business Marketing,

Dr. Sungmin Ryu is an associate professor of school of business at Sungkyunkwan University. He specializes in the areas of channels of distribution, business-to-business marketing, and global supply chain management. He has publications in Industrial Marketing Management, Journal of Business Research, Organization Science, Journal of Business and Industrial Marketing, Journal of Business-to-Business Marketing, and Journal of Marketing Channels, and others.

\section{REFERENCES}

1. Geyskens, I., Gielens, K., \& Dekimpe, G. (2002), The Market Valuation of Internet Channel Additions, Journal of Marketing, 66, 102-119.

2. Rosenbloom, B (2004), Marketing Channels ( $7^{\text {th }}$ Ed.), Mason, OH: South-Western. 